\title{
Experimental Investigation of the Matching Relationship between Asphalt Particle and Reservoir Pore in Profile Control Process
}

\author{
Chengfeng Ren, ${ }^{1}$ Junjian $\mathrm{Li}^{2}{ }^{2}$ Yiqiang Li, ${ }^{2}$ Jingshu Yuan, \\ Yanqiang Xi, ${ }^{2}$ Kang Xiao, ${ }^{2}$ and Yuxi Wang ${ }^{2}$ \\ ${ }^{1}$ The Sixth Oil Production Co., PetroChina Daqing Oilfield Company Ltd., Daqing 163000, China \\ ${ }^{2}$ China University of Petroleum, Beijing 102249, China
}

Correspondence should be addressed to Junjian Li; junjian_cup@163.com

Received 1 October 2015; Revised 5 January 2016; Accepted 10 February 2016

Academic Editor: Kohji Tashiro

Copyright (C) 2016 Chengfeng Ren et al. This is an open access article distributed under the Creative Commons Attribution License, which permits unrestricted use, distribution, and reproduction in any medium, provided the original work is properly cited.

\begin{abstract}
Modified sulfonated asphalt particles have a bright application prospect of the profile control of thick reservoirs due to the low cost, extensive sources, and good compatibility with reservoir. Nevertheless, the matching relationship between asphalt particles and reservoir pore has seldom been investigated till now. Oversized particles always block the near-wellbore area, which causes high injection pressures, while undersized particles cannot plug large pores. We designed a core for this experiment which has a high permeability zone in front of it and many pressure measuring points. We could quantitatively assess the matching relationship by measuring the on-way resistance coefficient, residual resistance factor, and relative change of permeability of man-made cores after injecting asphalt. Experimental results indicate that asphalt particles with sizes of $0.02 \mathrm{~mm}, 0.02-0.06 \mathrm{~mm}$, and $0.08-0.1 \mathrm{~mm}$ match with reservoir permeability of $500 \mathrm{mD}, 1000 \mathrm{mD}$, and $2000 \mathrm{mD}$, respectively. Undersized or oversized particles can reduce the conformance control effect, and the concentration of asphalt particles in the injectant can limit their migration ability. When the concentration of asphalt particles increases to $3000 \mathrm{mg} / \mathrm{L}$, accumulations of asphalt particles can be caused in the formation, in which a scheme with asphalt particles alternative water injection is proposed to avoid the accumulation.
\end{abstract}

\section{Introduction}

Lamadian Oilfield which is a mature thick positive rhythm reservoir in Daqing, coupled with the presence of low permeability intervals, is especially heterogeneous in vertical direction $[1,2]$. As water flood occurs continuously, preferential channels appear in the bottom high permeability layers of the reservoir, which brings about invalid injection water cycle in between injection wells and production wells, resulting in low water flood efficiency and high remaining oil saturation on the top of the reservoir [3-5].

Researchers have developed various methods to solve the aforementioned problem, among which profile control is an efficient and widely used one [6-8]. When profile control agent is injected into the reservoir, it enters the original high permeability layers first and reduces their transmissibility, which leads subsequent fluid to bypass these layers and enter the nonswept or poorly swept layers, thus enhancing the sweep efficiency. By now, weak gel is quite commonly used as profile control agent, which plugs high permeable layers by forming a network structure of crosslinked polymer [9-11]. However, weak gel as well as other frequently used agents has some weakness, such as high price, complex configuration procedure, and short validity time [12]. In recent years, researchers turned their eyes on asphalt particles and had done some preliminary laboratory experiments. At the same time, some field tests in Daqing Oilfield also showed fairly good profile modification results $[13,14]$. On one hand, asphalt micro-emulsion plugs high permeable layers by the physical plugging of the asphalt particles; on the other hand asphalt particles transform under high temperature and congeal onto the rock surface, further lowering the transmissibility. According to present researches, asphalt particles have many advantages, such as 
rich sources, low price, good compatibility with reservoir rocks (coming from the reservoir), and easy adherence to the rock surface under reservoir temperature.

In the experiment, the sulfonated modified asphalt is composed of four parts, which are saturated, aromatic, colloid, and asphaltene with SBS polymer and light calcium carbonate added at the same time. After modification, the modified process gives the priority to the physical modification. Its chemical structure unit did not change. When the polymer is added to the modified agent, the swelling and adsorption of the polymer modified agent can change the structure of the asphalt colloid and enhance the gel property of the asphalt. And three-dimensional network structures which are formed by the polymer molecules hinder the drop of a ball. So, the modified asphalt shows relative high suspension ability and also improves the stability under the high and low temperature. Therefore, when the injection pressure reaches a certain degree, the plugging agent can pass through the near-wellbore area of high permeability channels of the target layer for deep profile control. Those agents can improve the reservoir injection profile and swept volume of injected fluid.

Unfortunately, former researches have not solved these problems. First of all, most displacement experiments are conducted in sand pack models, which greatly affects the accuracy of the experimental results due to the large difference between sand pack models and the actual reservoir; secondly, some researchers used man-made cores to conduct the displacement experiment, which guarantees higher similarity to the actual reservoir, but asphalt particles often block the injection end and cannot enter the cores successfully which result in higher injection pressure and reduction of produced liquid. Therefore, the epoxy resin casting cores used in experiment have been improved. In order to avoid the blocking in the injection end, we add a high permeable section on the forepart of cores. The last and more important point is that no one has systematically studied the matching relationship of asphalt grain sizes and reservoir pore sizes until now. As Oversized particles block the injection end and undersized particles are incapable of blocking big pores, the matching relationship of asphalt particle sizes and target pore sizes determines the success of profile control. Therefore, we designed a new fluid drive unit to assess the matching relationship of asphalt particle sizes with pore sizes by measuring the on-way resistance coefficient, residual resistance factor, and relative change of permeability in man-made cores after injecting asphalt [15]. We hope this research would be a guide to the application of asphalt particles in profile control.

\section{Experiments}

2.1. Experiment Condition. The reservoir temperature of Lamadian Oilfield in Daqing is $45^{\circ} \mathrm{C}$. So the experimental process is carried out under the condition of reservoir temperature.

2.2. Experiment Principle. Injection pressure and flooding efficiency are judged by the compatibility of injection system and the reservoir. If the compatibility is bad, the injected fluid will jam in the pore and increase the injection pressure rapidly. As a consequence of this, the injected fluid cannot reach the target layer and achieve its aims. The realization about compatibility is based on the research on the compatibility of polymer and reservoir. Polymer is a kind of flexible group with certain feature sizes. Its size decides the compatibility of reservoir and polymer. So it can be an essential basis for polymer selection.

The compatibility of asphalt is differing from that of polymer because asphalt particles are a kind of rigid particles and the sizes vary in range. We cannot establish a direct relation between the sizes of particles and the pores' sizes. We can establish the relation by experiment. The compatibility of asphalt particles means the relation of particle sizes and the permeability of reservoirs. The appropriate particles have good performance on sealing the target layer and migration performance. The migration performance can be evaluated by the resistance coefficient in the different parts of the reservoir and the sealing performance can be evaluated by residual resistance factors and relative change of permeability.

We inject the profile control system in a speed of $1 \mathrm{~mL} / \mathrm{min}$ and inject $1.5 \mathrm{PV}$ totally. We observed that the injection pressure increases with the volume. We measure the residual resistance coefficient and plugging efficiency by the data about injection pressure.

Among them, the resistant coefficient is an important index to define the ability of controlling asphalt particle mobility; namely, the ability of asphalt particles reduces the mobility ratio, defined as the ratio of water's mobility to the asphalt particles solution's mobility:

$$
R_{F}=\frac{\lambda_{w}}{\lambda_{l}}=\frac{\left(k_{w} / \mu_{w}\right)}{\left(k_{l} / \mu_{l}\right)} .
$$

Residual resistance coefficient $\left(R_{k}\right)$ is to describe the reduction ability of permeability by asphalt particles, defined as the ratio between the water phase permeabilities of the rock before and after injection of asphalt particles, also known as the coefficient of permeability declined:

$$
R_{k}=\frac{k_{w b}}{k_{w a}}
$$

Relative change of permeability refers to the reduction of water phase permeability's percentage after the injection of asphalt percentage, whose expression is as follows:

$$
E=\frac{K_{w b}-K_{w a}}{K_{w b}} .
$$

In the formula above, $\lambda_{w}$ is the mobility of the water phase, $\mu \mathrm{m}^{2} / \mathrm{mPa} \cdot s ; \lambda_{l}$ is the mobility after the injection about the asphalt particle, $\mu \mathrm{m}^{2} / \mathrm{mPa} \cdot s ; R_{k}$ is residual resistance coefficient, dimensionless; $R_{F}$ is resistant coefficient, dimensionless; $E$ is relative change of permeability; $K_{w}$ is the permeability of the water phase, $\mu \mathrm{m}^{2} ; K_{w b}$ is the permeability of the core before the profile control in the system, $\mu \mathrm{m}^{2} ; K_{w a}$ is the permeability of the core after the profile control in the system, $\mu \mathrm{m}^{2}$. 


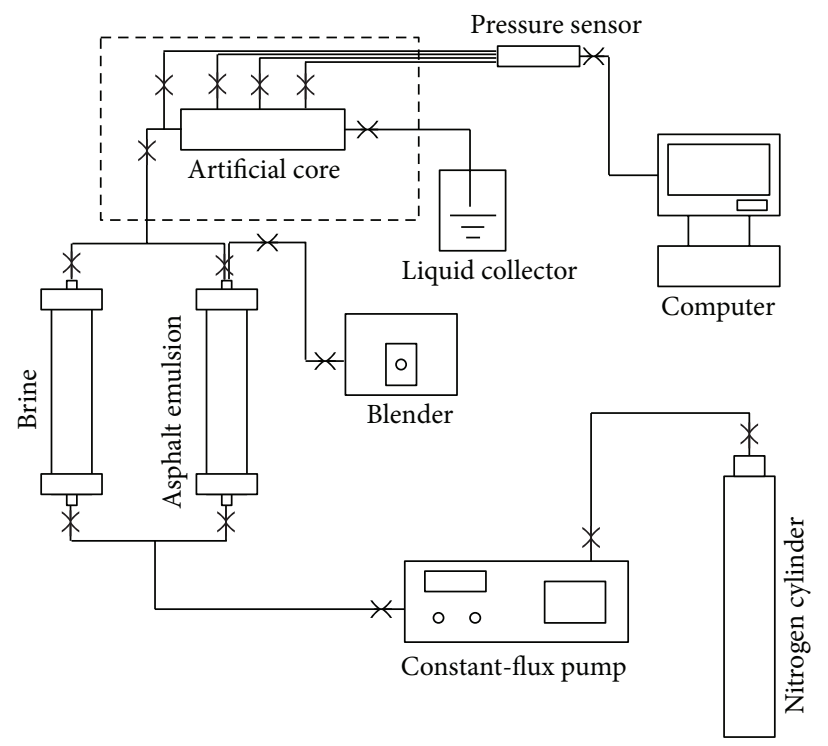

FIGURE 1: Experimental flow diagram.

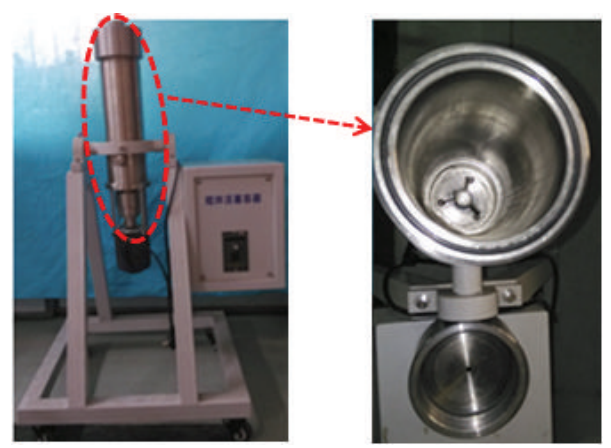

FIgURe 2: Piston vessel with blender.

2.3. Experimental Equipment. The diagram of experimental device is shown in Figure 1. We added a blender to the piston vessel in the experimental device to reduce the possibility of precipitation. By blending constantly, asphalt particles keep suspending in the water. The photo of the piston vessel is illustrated in Figure 2.

Compared to sand pack models, man-made cuboid cores that we used in the experiments are of much higher similarity to the actual reservoir. The cores are enfolded by epoxy resin and are capable of bearing a maximum pressure of $1 \mathrm{MPa}$. To avoid blocking cores' injection end by asphalt particles, we added a high permeability segment in each core, dispersing asphalt particles and ensuring that the asphalt micro-emulsion enters the cores easily, as shown in Figure 3. All the pipelines in the experiments are amplified from $3 \mathrm{~mm}$ to $6 \mathrm{~mm}$, allowing asphalt micro-emulsion to flow in a larger space, lowering the possibility of precipitation.

Apart from those aforementioned modules, the other experimental equipment does not change. A constant-flux pump is used for constant speed displacement or variable speed displacement, compressing fluid to flow in porous media. Its displacement velocity range is between $0.1 \mathrm{~mL} / \mathrm{h}$ and $600 \mathrm{~mL} / \mathrm{h}$ and the control accuracy is $0.01 \mathrm{~mL} / \mathrm{h}$. The thermostat we used has a control accuracy of $\pm 1^{\circ} \mathrm{C}$, building an experimental environment equal to the actual reservoir temperature, obtaining the transformation effect of asphalt particles. We also used three kinds of pressure sensors: low range pressure sensor DP130-26, with a measuring range of $3.5 \mathrm{KPa}$; medium range pressure sensor DT15-TL, with a measuring range of $35.0 \mathrm{KPa}$; high range pressure sensor DT15-TL, with a measuring range of $140 \mathrm{KPa}$. By connecting the sensors to a computer, we detected and collected the pressure data.

2.4. Materials. The water used in the experiments is on-site injection water. Its salinity composition is shown in Table 1.

The asphalt we used mainly consists of saturates, aromatics, colloid, and asphaltene, where the content of colloid and asphaltene is $77.5 \%$, with SBS polymer and light calcium carbonate added. To get experimental asphalt particles, the asphalt is further prepared by oxidization, sulfonation, and cooling grind. Taking the permeability range of the actual reservoir into consideration, asphalt particles of 5 grain sizes are prepared: $0.02 \mathrm{~mm}, 0.02-0.06 \mathrm{~mm}, 0.06-0.08 \mathrm{~mm}$, 
TABLE 1: Water salinity composition.

\begin{tabular}{lcccccccc}
\hline Dilution water $(\mathrm{mg} / \mathrm{L})$ & $\mathrm{Cl}^{-}$ & $\mathrm{SO}_{4}{ }^{2-}$ & $\mathrm{HCO}_{3}{ }^{-}$ & $\mathrm{CO}_{3}{ }^{2-}$ & $\mathrm{K}^{+}+\mathrm{Na}^{+}$ & $\mathrm{Ca}^{2+}$ & $\mathrm{Mg}^{2+}$ & Total salinity \\
\hline Fresh water & 54.79 & 31.41 & 236.61 & 15.51 & 68.92 & 41.50 & 18.55 & 467.28 \\
\hline
\end{tabular}

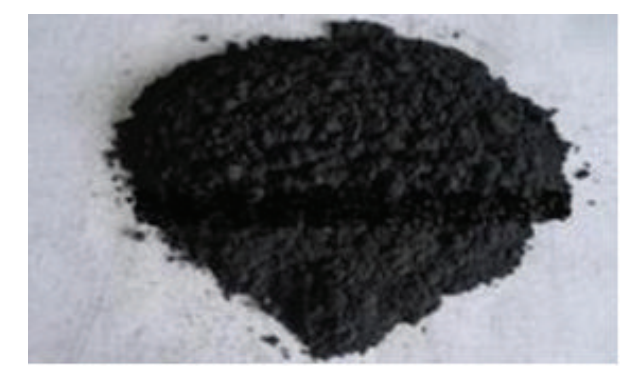

FIgURE 3: Asphalt particles of different grain sizes.

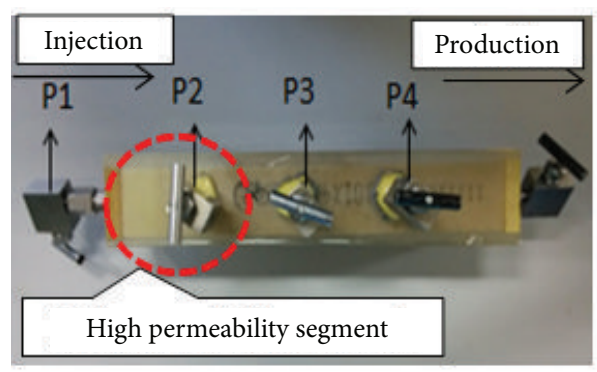

FIgURE 4: Diagram of man-made core and pressure sensors.

$0.08-0.1 \mathrm{~mm}$, and $0.1-0.3 \mathrm{~mm}$, as shown in Figure 3 . In the study on the sealing characteristics of asphalt particles, asphalt micro-emulsion of 3 concentrations was prepared: $1000 \mathrm{mg} / \mathrm{L}, 3000 \mathrm{mg} / \mathrm{L}$, and $5000 \mathrm{mg} / \mathrm{L}$.

The cores used in the experiments are man-made cuboid cores enfolded by epoxy resin. Their macroscopic permeability, porosity, and micro-pore structure are highly similar to the actual reservoir. The size of each core is $300 \times 45$ $\times 45 \mathrm{~mm}$ with a high permeability segment at one end to disperse asphalt particles (as mentioned in the last paragraph in Introduction). To measure the on-way pressure after injecting asphalt micro-emulsion, we uniformly set 4 pressure sensors along the core, as shown in Figure 4. We made cores of different permeabilities, that is, $500 \mathrm{mD}, 1000 \mathrm{mD}$, and $2000 \mathrm{mD}$, which nearly cover the permeability range of the actual reservoir.

2.5. Procedures. The main procedure of the experiment is as follows. Detailed process is illustrated in Figure 1.

(1) Measure the size of man-made cores. Weigh them, in preparation for calculating pore volume and porosity.

(2) Vacuumize the core and saturate the formation water, measure the core permeability by water, and calculate the porosity.

(3) Measure the core's permeability with water.
(4) Inject the profile control system constantly. The total injection quantity is 1.5 PV. Record the change of the pressure and the rate of flow.

(5) Water floods after injecting asphalt until the pressure difference at both ends of the core reaches stability again.

\section{Results and Discussion}

3.1. The Research of the Compatibility of Asphalt Particle Size and Core Permeability. Asphalt particle profile control is a method which can seal the high permeability area in the layer on the benefit of particle mechanical blockage effect. This method can expand swept volume and improve ultimate recovery. In addition, asphalt particles will cement with each other at high temperatures. The size of molecular thread becomes bigger, which is beneficial to seal the core pores. At the same time, the asphalt coil adheres to the core framework. This process will produce two kinds of forces. Before injecting asphalt micro-emulsion, we have an anionic surfactant preflush in order to change the wettability of rock. Therefore, when the anionic polar groups get in touch with the alkaline earth metal oxide core, spooning compound will be generated at the interface by the influence of molecular force. This kind of compound has strong adsorption capability. It can adhere to the surface of pore and seal the formation. 
TABLE 2: Experimental results.

\begin{tabular}{lccccccccccc}
\hline \multirow{2}{*}{$\begin{array}{l}\text { Permeability } \\
\mathrm{mD}\end{array}$} & \multirow{2}{*}{ Particle sizes } & \multicolumn{3}{c}{ Resistance coefficient } & \multicolumn{3}{c}{ Residual resistance factor } & \multicolumn{3}{c}{ Relative change of permeability \% } \\
& & Average & Front & End & Average & Front & End & Average & Front & End \\
\hline \multirow{3}{*}{500} & 0.02 & 19.27 & 22.16 & 15.94 & 7.77 & 6.96 & 8.7 & 87.13 & 85.64 & 88.5 \\
& $0.02-0.06$ & 24.32 & 39.24 & 7.25 & 8.78 & 13.29 & 3.62 & 88.62 & 92.48 & 72.4 \\
& $0.06-0.08$ & 28.04 & 46.84 & 6.52 & 12.5 & 20.89 & 2 & 92.00 & 95.21 & 65.5 \\
& $0.08-0.1$ & 33.11 & 56.96 & 5.80 & 17.06 & 30.38 & 1.81 & 94.14 & 96.71 & 44.8 \\
& $0.1-0.3$ & 34.12 & 60.12 & 4.35 & 20.27 & 36.71 & 1.45 & 95.07 & 97.28 & 65.5 \\
\hline \multirow{3}{*}{1000} & 0.02 & 9.46 & 10.13 & 8.7 & 6.76 & 5.06 & 8.7 & 85.20 & 80.25 & 88.5 \\
& $0.02-0.06$ & 17.57 & 19.94 & 14.13 & 6.08 & 6.65 & 6.52 & 83.56 & 84.2 & 82.75 \\
& $0.06-0.08$ & 20.27 & 24.05 & 15.94 & 5.41 & 7.59 & 2.9 & 81.50 & 86.83 & 65.5 \\
& $0.08-0.1$ & 21.62 & 26.88 & 17.88 & 6.42 & 10.12 & 2.17 & 84.42 & 90.12 & 54 \\
& $0.1-0.3$ & 25.68 & 27.84 & 23.19 & 8.78 & 15.19 & 1.45 & 88.62 & 93.42 & 31 \\
\hline \multirow{3}{*}{2000} & 0.02 & 4.73 & 6.30 & 2.90 & 6.08 & 3.8 & 8.7 & 83.56 & 73.67 & 88.5 \\
& $0.02-0.06$ & 9.5 & 10.10 & 8.70 & 5.41 & 2.53 & 8.7 & 81.50 & 60.5 & 88.5 \\
& $0.06-0.08$ & 11.49 & 12.70 & 10.10 & 5.41 & 3.8 & 7.25 & 81.50 & 73.67 & 86.2 \\
& $0.08-0.1$ & 12.67 & 14.24 & 10.87 & 6.33 & 7.12 & 5.43 & 84.21 & 85.96 & 81.6 \\
& $0.1-0.3$ & 16.22 & 20.25 & 11.59 & 9.46 & 15.19 & 2.89 & 89.43 & 93.42 & 65.5 \\
\hline
\end{tabular}

Without the consideration of the interaction between various factors, we select the resistance coefficient, residual resistance coefficient, and relative change of permeability to research the matching relation between asphalt particle size and permeability.

According to the experimental data of different points, P1P2 segment is a transition section with high permeability. Pressure in this segment is low. So the asphalt particles can pass this segment smoothly. Therefore, we can analyze the injecting performance and sealing performance of asphalt particles by analyzing injection pressure difference of P2P3 and $\mathrm{P} 3 \mathrm{P} 4$.

As can be seen from Table 2, asphalt particle size and core permeability have the compatibility between the asphalt particles and reservoirs. Under different core permeability, the flow resistance and the resistance coefficient and residual resistance coefficient increase with the increase of asphalt particle size. There are some differences of different particle size characteristics in different permeability cores. Small particle size not only can establish a higher flow resistance, but also has good transport capability under low permeability $(500 \mathrm{mD})$. The resistance coefficients of the beginning and the end of these core segments are high. But with increase of the size of asphalt particles, the transmission ability of the particles migration will be weakened and the difference of coefficient becomes larger, although the flow resistance is increasing (Figure 5 pitch residual stranded in the core of the particles). At the same time, it can be seen from the table that when the permeability keeps constant $(500 \mathrm{mD})$, residual resistance factor and plugging increase with the size change, which do not comply with certain rules. The main reason is that the particle with small size has good performance in cementation and sealing. Blocking of the formation with the large size of particles mainly depends on their physical size. We can draw a conclusion that the particles of different size have different influences on sealing and changing the residual resistance coefficient. So we should know about their differences in the field application.

When the core permeability is high $(>1000 \mathrm{mD})$, the particles of small size have a good transport capability. But their flow resistance in the core is lower. In this case, when the asphalt particle size increased within a certain range, the transmission ability of the particles migration will not be affected and the injection pressure will be improved. But when the particle size is over large, the ability of particle's transmission and migration will decrease. That means those particles gather in the injection side and cause the blocking in the near bore area. It can also cause the increase of the injection pressure and the decrease of the produced fluid volume. As we can see, when we choose the asphalt particle for different reservoirs with different permeability, we should consider the transmission ability as well as whether the particles can achieve a high penetrating resistance. We can reach the goal of profile control of deep reservoirs, improve the fluid diversion, enlarge the swept volume, and enhance oil recovery in this way.

In conclusion, the relationship between the different permeability formations and matching different size particles of asphalt has been established.

Through Table 3 we could see the relationship between permeability and particle size is about 0.6 to 0.8 times which we have obtained. The particle sizes are mainly concentrated in the $20 \mu \mathrm{m}$ and $80 \mu \mathrm{m}$, respectively, after a rigorous screening. Bridging phenomenon occurred in the pore throat under the influence of bonding, adhesion between particles and formation temperature after the injection of the profile control agent into the formation. Then it plugged the high permeability layer and played the role of profile control. 
TABLE 3: Relative relationship.

\begin{tabular}{lccc}
\hline Water permeability $(\mathrm{mD})$ & Pore throat size of core $(\mu \mathrm{m})$ & Grains of asphalt $(\mu \mathrm{m})$ & Relative relationship (particle size/pore throat size) \\
\hline 500 & 36.77 & 20 & $54.39 \%$ \\
1000 & 62.14 & $20-60$ & $32.18 \%-96.55 \%$ \\
2000 & 103.28 & $80-100$ & $77.45 \%-96.8 \%$ \\
\hline
\end{tabular}

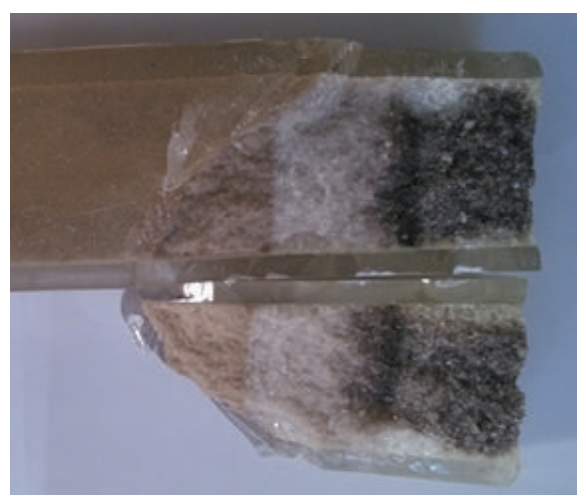

(Particle size $0.02-0.06 \mathrm{~mm}$ )

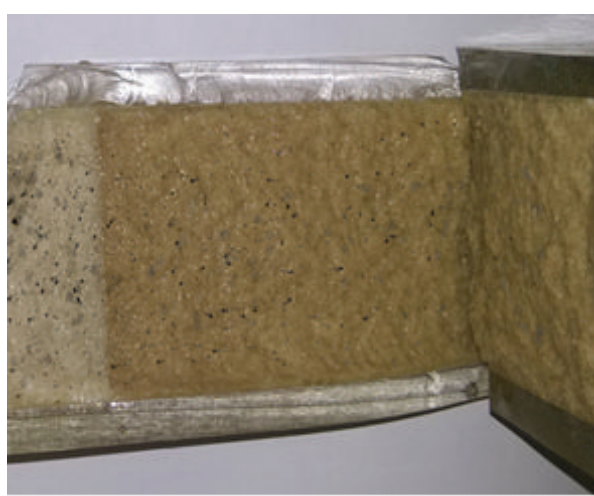

(Particle size $0.1-0.3 \mathrm{~mm}$ )

FIgURE 5: Core cleaving comparison chart.

3.2. The Study of Sealing Characteristics of Asphalt Particles. The concentration of asphalt particles has a significant effect on the sealing performance. Under the condition of the constant injection pore volume, when the concentration decreases and less particles enter into the core, the residual resistance factor and relative change of permeability become smaller. In the condition to make sure that the permeability and asphalt particle size keep constant, we are studying the effect of concentration for the sealing performance.

In this experiment, by the conclusion which we got in the study about matching relation between particle size and permeability, in the study of the core permeability of $500 \mathrm{mD}$, $1000 \mathrm{mD}$, and core $2000 \mathrm{mD}$, we use the asphalt particle with the size of $0.02 \mathrm{~mm}, 0.02-0.06 \mathrm{~mm}$, and $0.08-0.1 \mathrm{~mm}$ to do the experiment. Without considering the circumstances of the interaction between various factors, select the three parameters (resistance coefficient, residual resistance factor, and relative change of permeability) to study the matching relation between asphalt particle concentration and permeability. According to amount of measured data of pressure measuring point, we can analyze the performance of asphalt particles injection and sealing performance.

From Table 4 and Figure 6, it can be confirmed that system of asphalt particles is influential on the sealing performance. In this experiment, the passage capacity of the profile control agent is evaluated by the resistance coefficient, residual resistance factor, and relative change of permeability, which is mainly used to evaluate the sealing performance of profile control agent. So when the core permeability is lower $(500 \mathrm{mD})$, with the increase of the concentration, the seepage resistance of injection process increases, when the resistance coefficient and residual resistance coefficient are increasing. From the difference about resistance coefficient between the front end and back end we can know that,

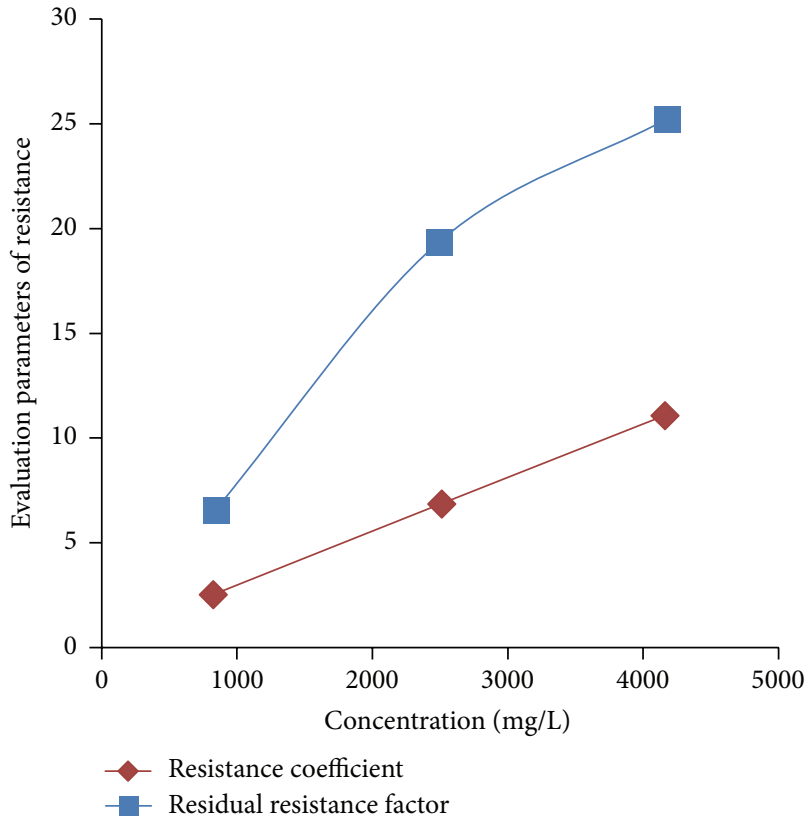

FIGURE 6: Relationship between resistance evaluation parameters and asphalt particles concentration $(500 \mathrm{mD})$.

with the increase of concentration, resistance changes in different locations. When the concentration increases from $1000 \mathrm{mg} / \mathrm{L}$ to $3000 \mathrm{mg} / \mathrm{L}$, the resistance coefficient in the back is increasing; this suggests that when concentration of asphalt emulsion is low, the stability of system, the particle migration in the core, and the sealing effect are good. But when the concentration increased from $3000 \mathrm{mg} / \mathrm{L}$ to $5000 \mathrm{mg} / \mathrm{L}$, the resistance coefficient at the front end increases largely, 


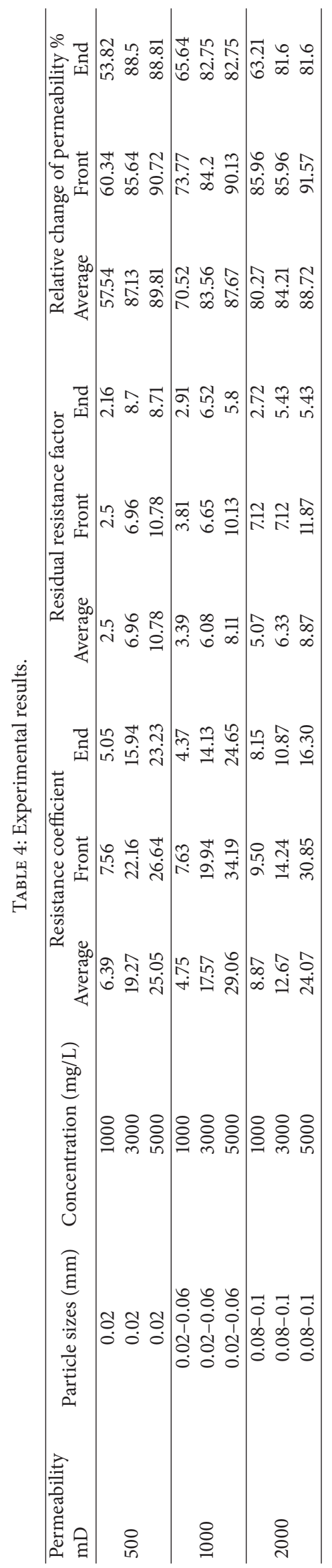




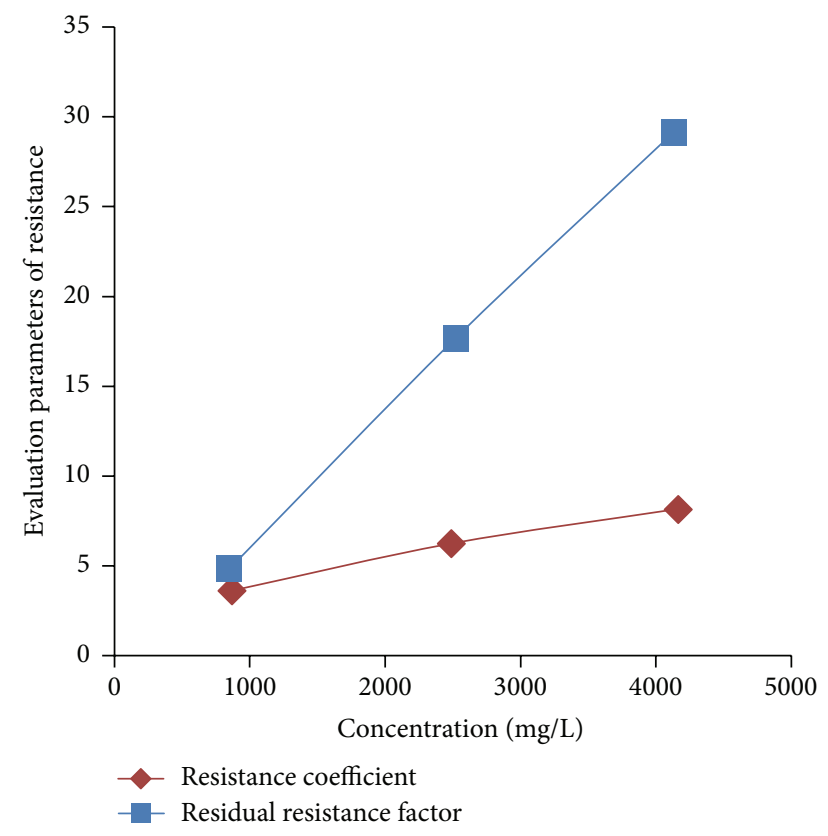

FIGURE 7: Relationship between resistance evaluation parameters and asphalt particles concentration $(1000 \mathrm{mD})$.

which shows that asphalt particles mainly accumulated in the wellbore zone with jamming, the main reason of which is that when the concentration of particles increased, the coalescence between them is more serious, with the part of the precipitate particles to form micelle setting, and the size of micelle is larger than the pore size. Therefore, the formation is blocked which led to the rising of injection pressure. At the same time, the determination of residual resistance factor and relative change of permeability in Table 4 , we can clearly find the change rule with resistance coefficient.

Although the three parameters are increasing with the concentration, its variation does not meet certain principle. So according to the data in the table, we can analyze the relationship between the particle size and stability: the smaller the particle size, the larger the effect of the concentration on the stability. This is primarily due to the small particle aggregation which is more serious than larger particles. In addition, the larger the particle size, the more rapid the precipitation. Stable performance is better with the larger particle size, and the factors of which large particles influence the stability are mainly settling.

Similarly, from Table 4 and Figures 7 and 8 , it can be seen that when the core permeability is high $(>1000 \mathrm{mD})$, the resistance coefficient, residual resistance factor, and relative change of permeability in the process of injecting are greater with asphalt particle concentration increased. Besides, the differences of these three parameters are the same as the core test of $500 \mathrm{mD}$, when the concentration is increased from $1000 \mathrm{mg} / \mathrm{L}$ to $3000 \mathrm{mg} / \mathrm{L}$. The three parameters have a larger increase in the posterior segment, while the concentration increases from $3000 \mathrm{mg} / \mathrm{L}$ to $5000 \mathrm{mg} / \mathrm{L}$, which have a larger increase in the former segment. Therefore, the above studies

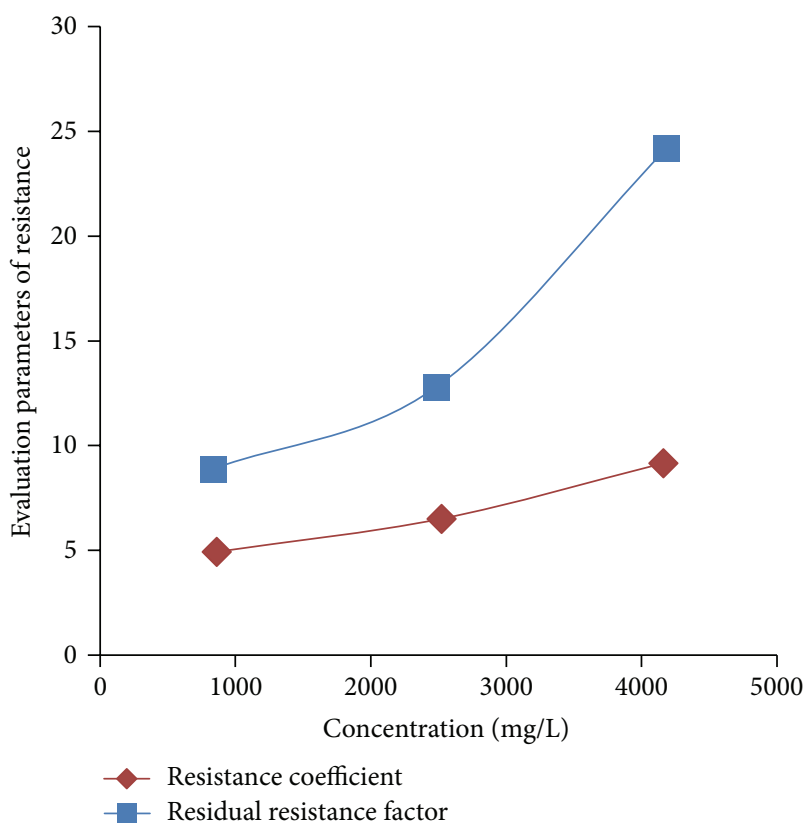

FIGURE 8: Relationship between resistance evaluation parameters and asphalt particles concentration $(2000 \mathrm{mD})$.

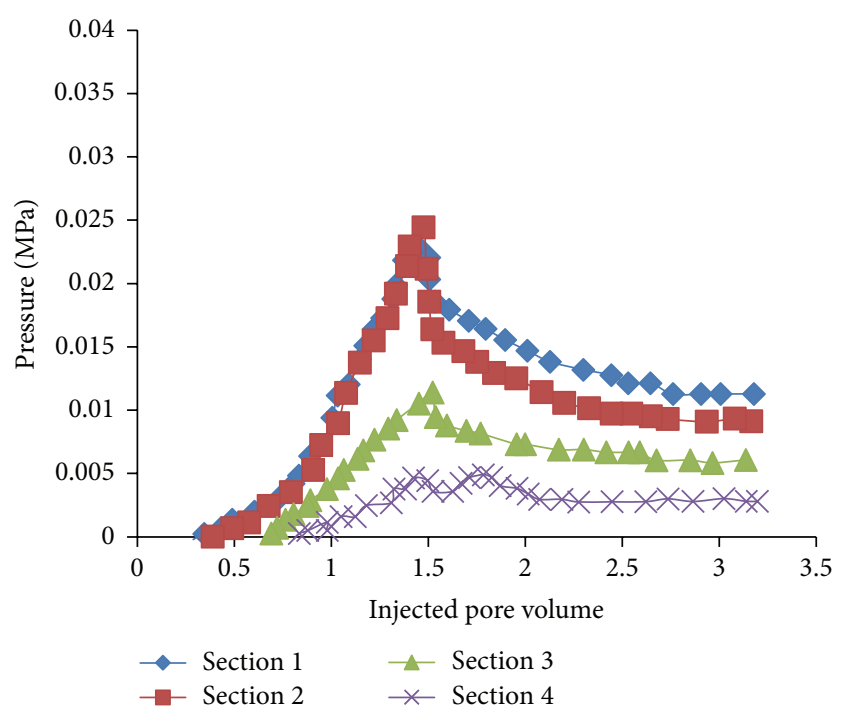

FIGURE 9: The plot of the injection pressure (diameter: $0.02 \mathrm{~mm}$, concentration: $1000 \mathrm{mg} / \mathrm{L}$ ).

show that when particle size is constant, asphalt particle solution is more stable with the lower concentration.

The relation between injection pressure and injected volume in different concentrations could be discovered in Figures 9-17 as when we inject the asphalt particles (less than 1.5 PV), the pressure increases with the increase of injected volume. This phenomenon indicates that the asphalt particles can expand the macro swept volume, for example, in the experiment with core permeability in $500 \mathrm{mD}$ and asphalt particles diameter in $0.02 \mathrm{~mm}$. When the slug size is the same, the pressure drops in both ends of core are not obvious 


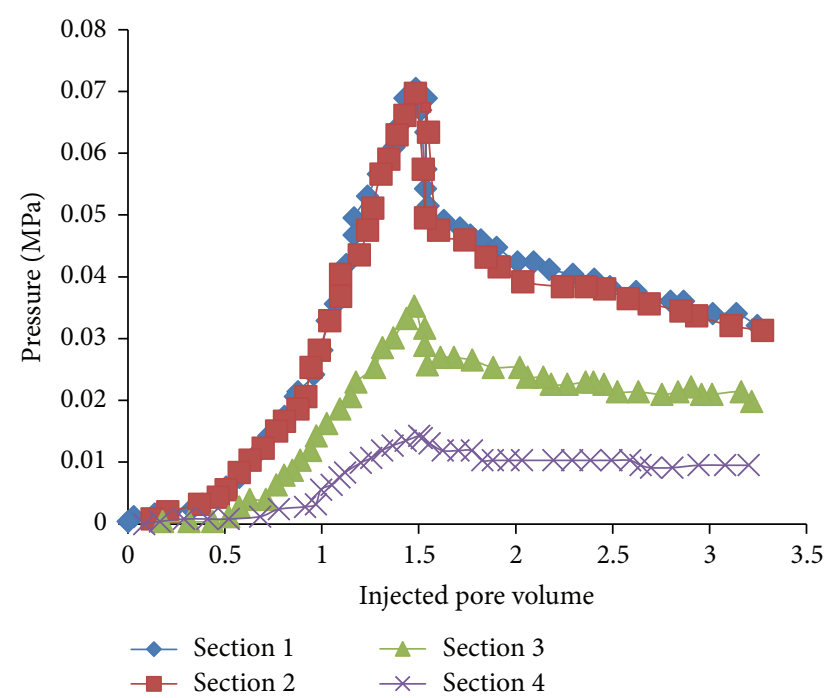

FIGURE 10: The plot of the injection pressure (diameter: $0.02 \mathrm{~mm}$, concentration: $3000 \mathrm{mg} / \mathrm{L}$ ).

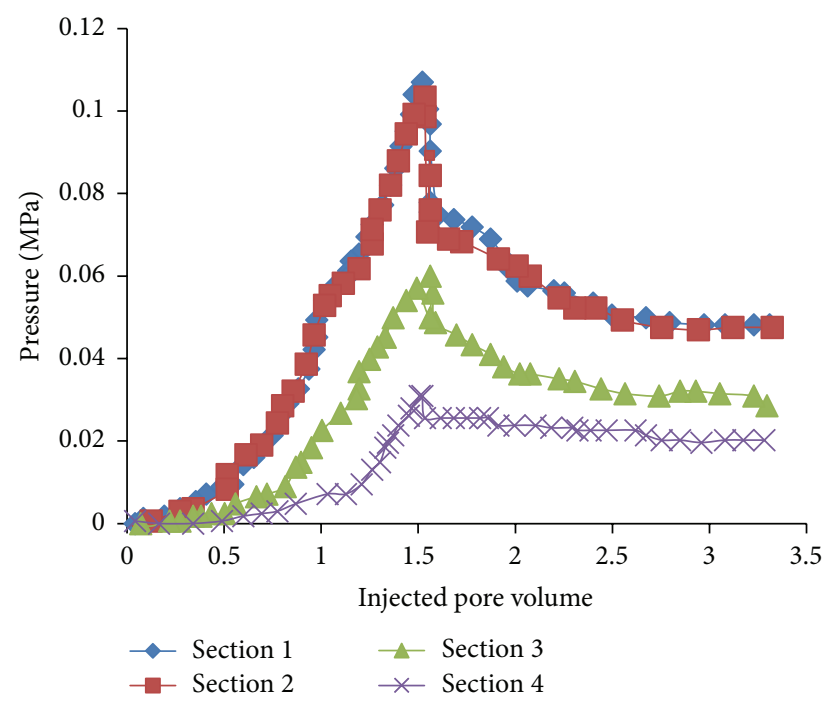

Figure 11: The plot of the injection pressure (diameter: $0.02 \mathrm{~mm}$, concentration: $5000 \mathrm{mg} / \mathrm{L}$ ).

under the asphalt particle concentration in $1000 \mathrm{mg} / \mathrm{L}$. When the concentration is increasing, the pressure in injection end increases and the pressure drop in production end becomes bigger and bigger. When the concentration reached $5000 \mathrm{mg} / \mathrm{L}$ and injection pressure is $0.11 \mathrm{MPa}$ high, this result verified the previous conclusion that the smaller the particle size, the greater the impact on the stability, and particle coalescence phenomenon becomes more serious. Those little particles stack in the immediate vicinity of wellbore and cause blocking. During subsequent water flooding stage $(>1.5 \mathrm{PV})$, the injection pressures (measured in injection end) in different particle concentrations dropped rapidly first and then become flat. The descent range in the experiments with particle concentration in $1000 \mathrm{mg} / \mathrm{L}-3000 \mathrm{mg} / \mathrm{L}$ is relatively small. It means water flooding transports the asphalt particles

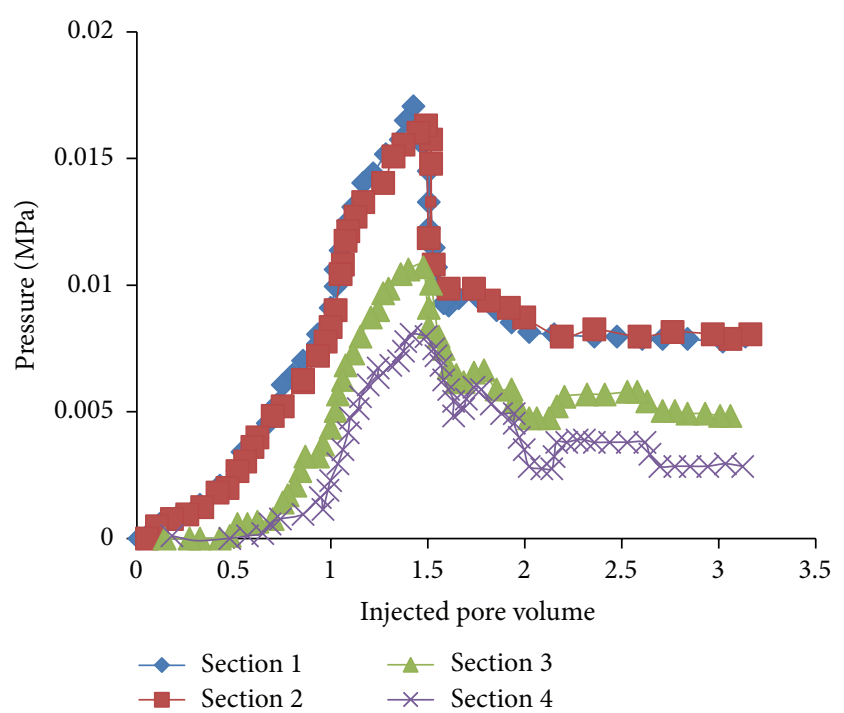

Figure 12: The plot of the injection pressure (diameter: 0.02$0.06 \mathrm{~mm}$, concentration: $1000 \mathrm{mg} / \mathrm{L}$ ).

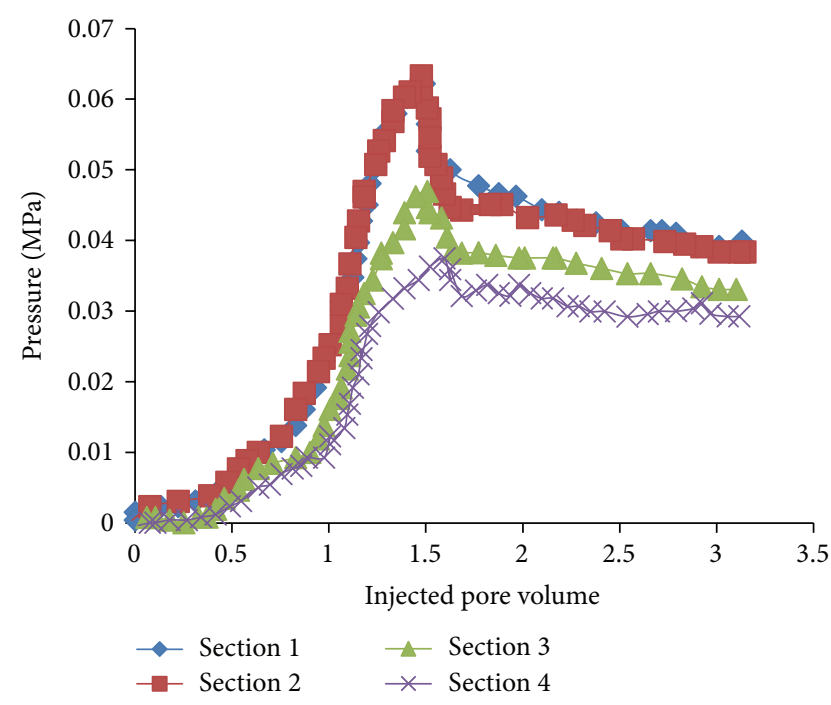

FIgURE 13: The plot of the injection pressure (diameter: 0.02$0.06 \mathrm{~mm}$, concentration: $3000 \mathrm{mg} / \mathrm{L}$ ).

to the back end and the deep profile control is achieved. It is beneficial to enlarge the swept volume.

In conclusion, particle concentration affects the compatibility significantly. The asphalt solution with concentration in $1000 \mathrm{mg} / \mathrm{L}-3000 \mathrm{mg} / \mathrm{L}$ has a great performance in stability and deep profile control. High concentration asphalt particle solution can be alternated with water which has a great performance in this way. At the same time, the relationship between injection pressure and injected volume under different concentration has been studied. Asphalt particle injection pressures rise in a row, and the pressure rising trend has a significant difference with polymer flooding. The regularity on particle accumulation and continuous phase viscosity control are different from polymer flooding. Therefore, pressure changing needs to be paid close attention 


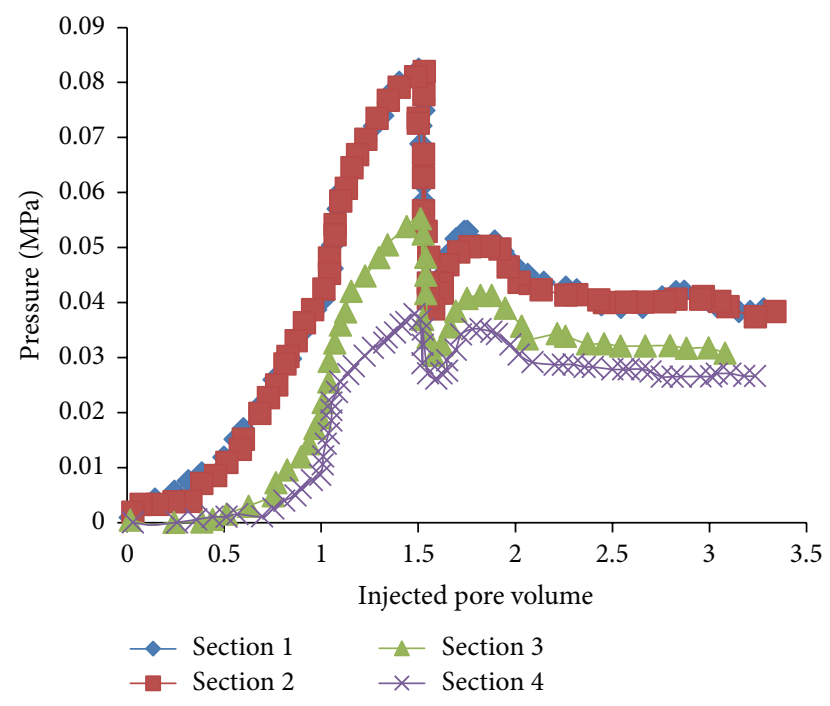

Figure 14: The plot of the injection pressure (diameter: 0.02$0.06 \mathrm{~mm}$, concentration: $5000 \mathrm{mg} / \mathrm{L}$ ).

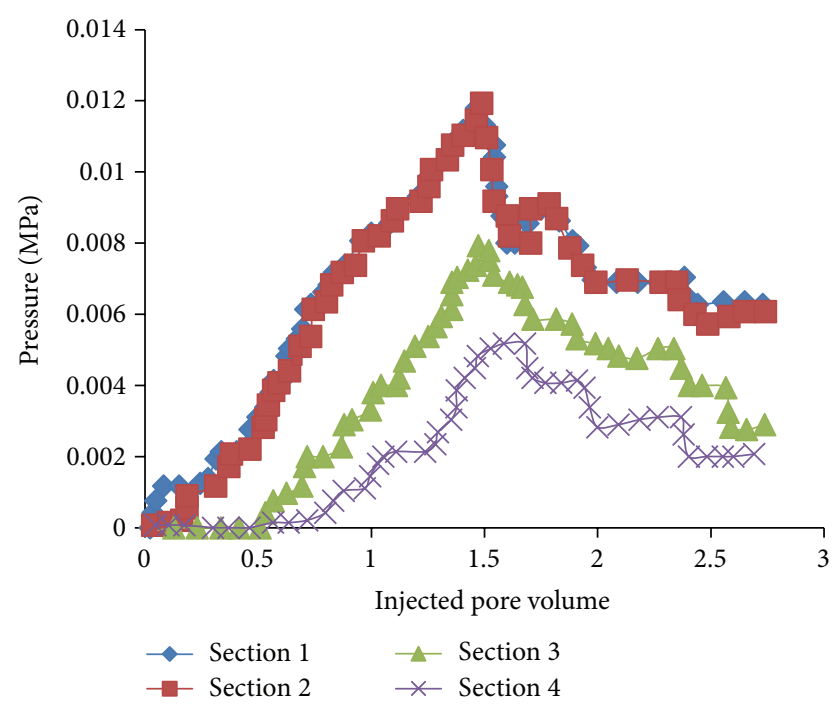

FIGURE 15: The plot of the injection pressure (diameter: 0.08$0.1 \mathrm{~mm}$, concentration: $1000 \mathrm{mg} / \mathrm{L}$ ).

in worksite, and the time interval of pressure surveillance should be shortened.

\section{Conclusions}

(1) In order to avoid asphalt precipitation in the experiments, we added a blender to the piston vessel and enlarged the pipeline inner diameter from $3 \mathrm{~mm}$ to $6 \mathrm{~mm}$, allowing asphalt particles to keep suspending in water, thus making the simulation environment more close to the actual formation.

(2) To ensure that the asphalt particles enter the core successfully, we added a high permeability segment at the injection end of every core, in order to avoid blocking at the injection end.

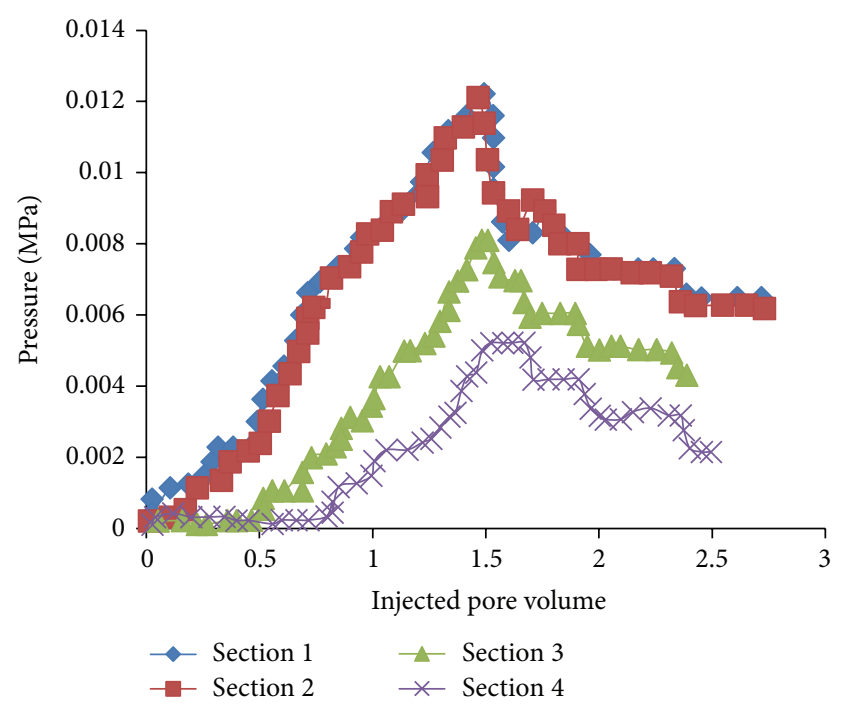

FIGURE 16: The plot of the injection pressure (diameter: 0.08$0.1 \mathrm{~mm}$, concentration: $3000 \mathrm{mg} / \mathrm{L}$ ).

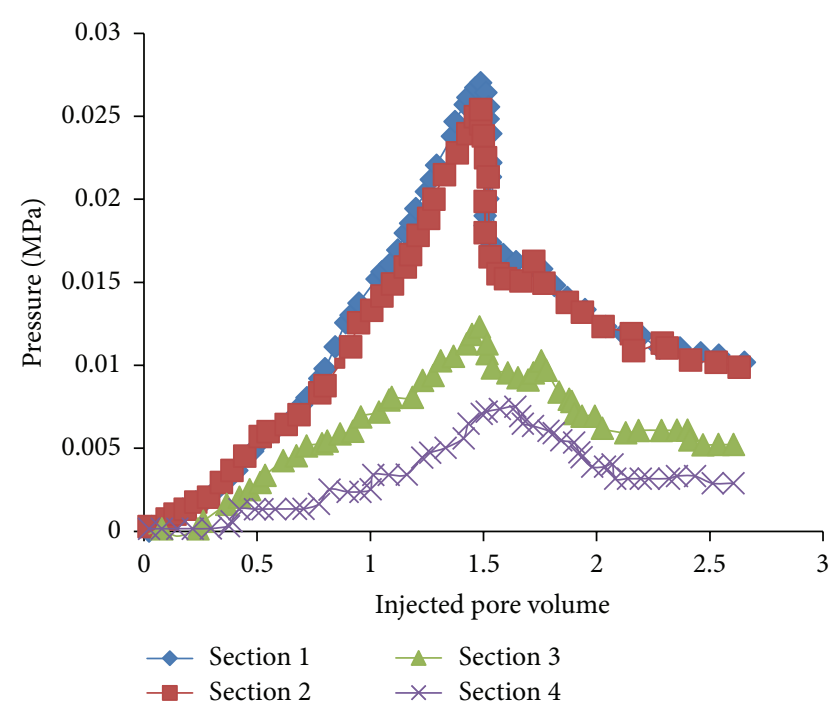

FIgURE 17: The plot of the injection pressure (diameter: $0.08-$ $0.1 \mathrm{~mm}$, concentration: $5000 \mathrm{mg} / \mathrm{L}$ ).

(3) We measured pressures of different sections after injecting asphalt micro-emulsion and got the resistance coefficient, residual resistance factor, and relative change of permeability of different part of the cores, thus evaluating the asphalt particles' capability to change mobility and to reduce the relative permeability of water. By analyzing the dynamic similarity of both ends of cores, we finally got the matching relationship of asphalt particles and core permeability; that is, cores of $500 \mathrm{mD}, 1000 \mathrm{mD}$, and $2000 \mathrm{mD}$ correspond with asphalt particles of $0.02 \mathrm{~mm}, 0.02-$ $0.06 \mathrm{~mm}$, and $0.08-0.1 \mathrm{~mm}$, respectively.

(4) The concentration of asphalt particle has an important influence on the injection performance and 
sealing performance. When the particle size is constant, the lower the concentration of asphalt particle solution is, the more stable they are.

(5) Modified sulfonate asphalt profile control agents' flow ability and relative stability are not affected by carrying liquid. It is cheap and has no corrosion on equipment. Asphalt particle solution with concentration in $3 \mathrm{~g} / \mathrm{L}$ and particle size in $0.08-0.1 \mathrm{~mm}$ has great compatibility with high permeability layer of Daqing Lamadian Oilfield with permeability in $2 \mu \mathrm{m}^{2}$. When the concentration is too high, it can be alternately injected with water in order to restrain the pressure increasing rapidly. Asphalt particle injection pressures rise in a row. Therefore, it is recommended that pressure changing needs to be paid close attention in worksite and the time interval of pressure surveillance should be shortened.

\section{Competing Interests}

Chengfeng Ren, Junjian Li, Yiqiang Li, Jingshu Yuan, Yanqiang Xi, Kang Xiao, and Yuxi Wang declared that there are no competing interests regarding the publication of this paper, in 2015/10/1.

\section{Acknowledgments}

The authors would like to thank the Scientific Research Foundation of China National Offshore Oil Corporation (no. YXKY-2014-ZY-03) for funding this research.

\section{References}

[1] Y. Liu, J. Hou, B. Song, X. Zhou, H. Chen, and L. Zhang, "Characterization of interlayers within braided-river thick sandstones: a case study on the Lamadian Oilfield in Daqing," Acta Petrolei Sinica, vol. 32, no. 5, pp. 836-841, 2011.

[2] Y.-B. Lin, J. Zhang, X.-G. Liu, and H.-T. Zhou, "Pore structure features of reservoirs at late high water-cut stage, Lamadian Oilfield, Daqing, China," Petroleum Exploration and Development, vol. 35, no. 2, pp. 215-219, 2008.

[3] C. Chen, X. Song, and J. Li, "Dominant flow channels of pointbar reservoirs and their control on the distribution of remaining oils," Acta Petrolei Sinica, vol. 33, no. 2, pp. 257-263, 2012.

[4] M. Sun and Z. Li, "Identification and description of preferential path for water-flooding sandstone reservoir," Xinjiang Oil \& Gas, vol. 5, no. 1, pp. 51-56, 2009.

[5] L. Jiang and Z. Wang, "Water invasion characteristics and potentiality analysis of Daqing Sapu reservoir in high water cut stage," Oil \& Gas Field Surface Engineering, vol. 26, no. 5, pp. 26-27, 2007.

[6] R. C. Smith and R. J. Steffensen, "Interpretation of temperature profiles in water-injection wells," Journal of Petroleum Technology, vol. 27, no. 6, Article ID SPE-4649-PA, pp. 777-784, 1975.

[7] H. H. Kaveler and Z. Z. Hunter, "Observations from profile logs of water injection wells," Journal of Petroleum Technology, vol. 4, no. 5, Article ID SPE-133-G, 1952.

[8] P. Glenat, G. Zaborowski, and A. Loppinet, "Profile modification in water injection wells by polymer treatments," in
Proceedings of the Abu Dhabi International Petroleum Exhibition and Conference, SPE-36212-MS, Abu Dhabi, UAE, October 1996.

[9] Y. Shiyi, M. Dong, W. Qiang, and Y. Hua, "Numerical simulation study on weak gel injection," in Proceedings of the SPE Asia Pacific Oil and Gas Conference and Exhibition, Winning Technology and Teamwork (APOGCE '00), pp. 197-206, Brisbane, Australia, October 2000.

[10] A. Al-Ibadi and F. Civan, "Experimental investigation and correlation of treatment in weak and high-permeability formations by use of gel particles," SPE Production \& Operations, vol. 28, no. 4, Article ID SPE-153557-PA, pp. 387-401, 2013.

[11] J. D. Purkaple and L. E. Summers, "Evaluation of commercial crosslinked polyacrylamide gel systems for injection profile modification," in Proceedings of the SPE Enhanced Oil Recovery Symposium, SPE-17331-MS, Society of Petroleum Engineers, Tulsa, Okla, USA, April 1988.

[12] J. Zhao, X. Kang, and J. Zhan, "Domestic progress of oil field profile control technology," Metal Materials and Metallurgy Engineering, vol. 40, no. 1, pp. 65-71, 2012.

[13] X. Lin, K. Yang, and J. Li, "Study on the stability of SBR latex modified asphalt," Petroleum Asphalt, vol. 20, no. 2, pp. 19-22, 2006.

[14] B. Gao, "Bitumen particles profile control technique in Lamadian Oilfield," Daqing Petroleum Geology and Development, vol. 25, no. 4, pp. 96-97, 2006.

[15] T. Wu, H. Li, X. Yi, and Y. Zhang, "Core plugging performance tests for graft starch polymer," Drilling \& Production Technology, vol. 31, no. 5, pp. 121-124, 2008. 

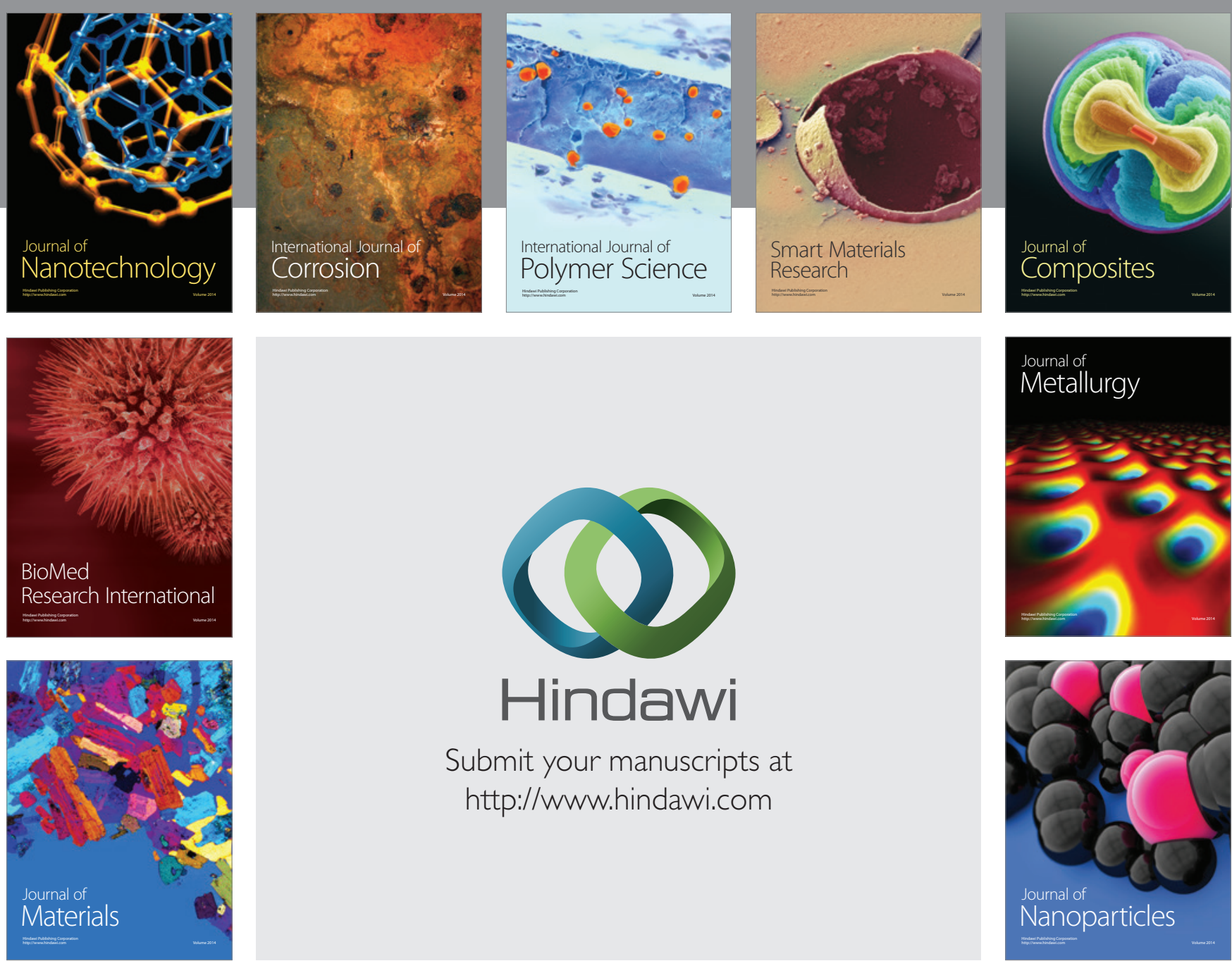

\section{Hindawi}

Submit your manuscripts at

http://www.hindawi.com

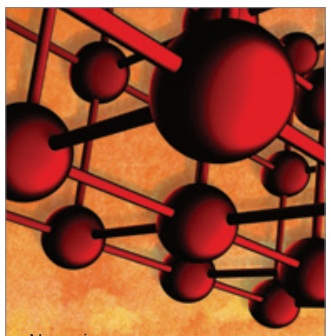

Materials Science and Engineering
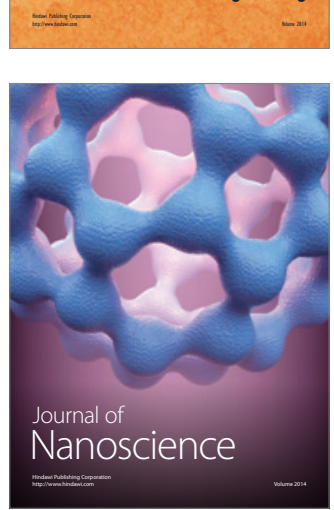
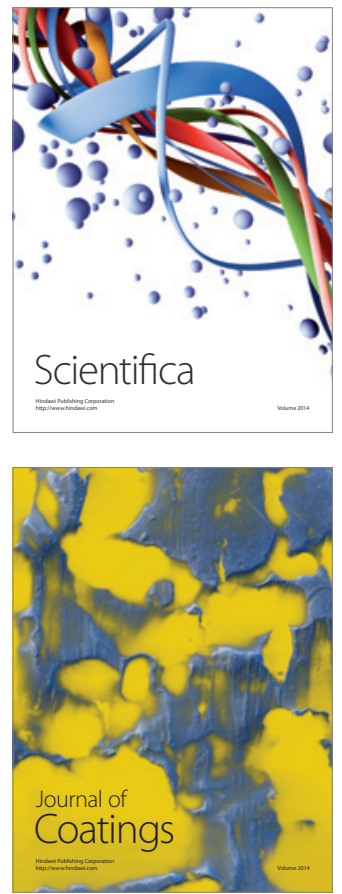
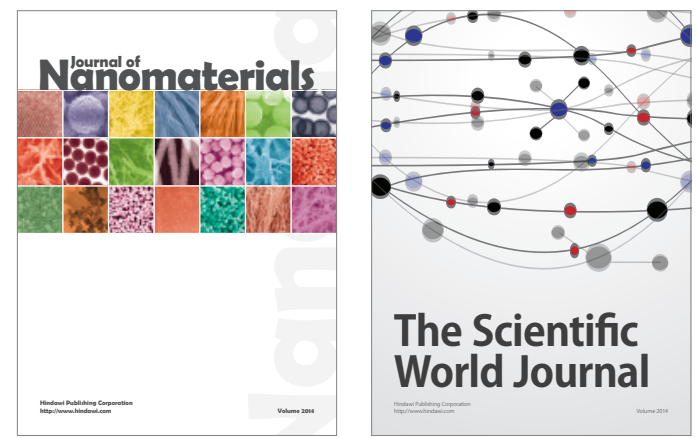

The Scientific World Journal
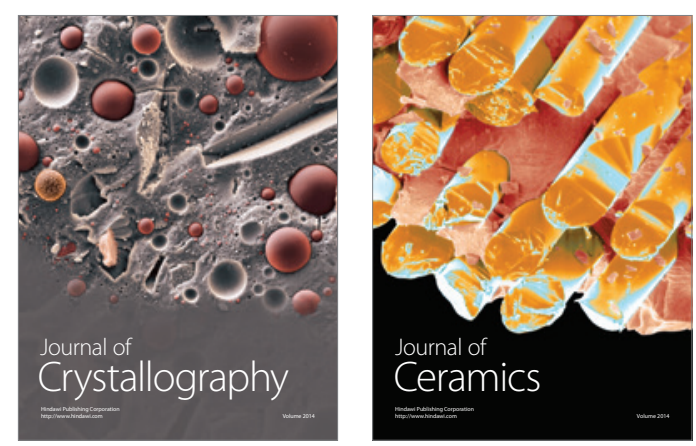
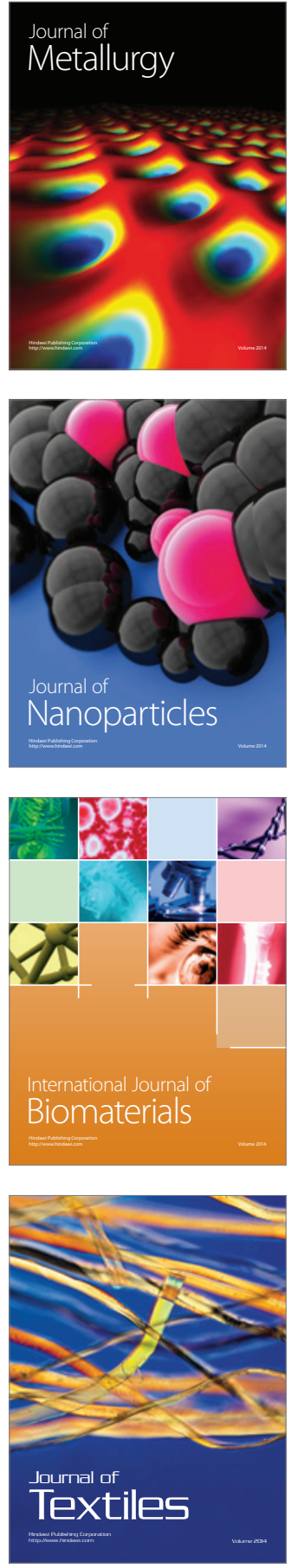